\title{
THE ECONOMICS OF RELIGION, JEWISH SURVIVAL AND JEWISH ATTITUDES TOWARD COMPETITION ON TORAH EDUCATION
}

\author{
Dennis W. Carlton \\ Avi Weiss \\ Working Paper 7863 \\ http://www.nber.org/papers/w7863
NATIONAL BUREAU OF ECONOMIC RESEARCH 1050 Massachusetts Avenue
Cambridge, MA 02138
August 2000

Forthcoming in Journal of Legal Studies. We thank Barry Chiswick, Deborah Dobrusin, Steven Katz, Aaron Levine, Gregory Pelnar, Eric Posner, Alex Raskovich, Jacob Rosenberg, Rabbi Gershon Seif, Robert Stillman, an anonymous referee and participants at the International Conference on Law, Jewish Law and Economics, held at Bar-Ilan University in December 1998, for helpful comments. The views expressed herein are those of the authors and not necessarily those of the National Bureau of Economic Research.

(C) 2000 by Dennis W. Carlton and Avi Weiss. All rights reserved. Short sections of text, not to exceed two paragraphs, may be quoted without explicit permission provided that full credit, including $\odot$ notice, is given to the source. 
The Economics of Religion, Jewish Survival and Jewish Attitudes Toward

Competition in Torah Education

Dennis W. Carlton and Avi Weiss

NBER Working Paper No. 7863

August 2000

\begin{abstract}
This paper examines the attitude of Jewish law to competition in light of the economist's understanding of the benefits of competition and of the beneficiaries from intervention in the competitive process. The punchline of this paper is simple. Although Judaism has used a whole host of restrictions on competition and has had its share of legislation to promote private interests, there has been one area that has generally been a consistent exception to impediments to competition -- the teaching of Torah. This exception is all the more remarkable because those who were in a position to influence the legislation often stood to benefit from such restrictions. From this stress on teaching, we show that the foundation was laid for the survival and perpetuation of Judaism.
\end{abstract}

Dennis W. Carlton

Graduate School of Business

The University of Chicago

1101 East $58^{\text {th }}$ Street

Chicago, IL 60637

and NBER

dennis.carlton@gsb.uchicago.edu
Avi Weiss

Bar-Ilan University

IZA

Department of Economics 52900 Ramat-Gan

ISRAEL 


\section{Introduction}

This paper examines the attitude of Jewish law to competition in light of the economist's understanding of the benefits of competition and of the beneficiaries from intervention in the competitive process. There are at least two reasons to use economics to understand Jewish law and we will illustrate both. First, the straightforward application of economics to halacha (Jewish law) can be of historical interest -- figuring out how certain laws impeded or accelerated economic developments and which groups were harmed and which helped. This type of analysis is akin to a study of current day antitrust policy or regulation in which one figures out which group benefitted from the government intervention and whether the intervention was based on an uninformed understanding of economics (though the failure to understand economics is a more serious criticism today than hundreds or even thousands of years before economics was developed as a science). The second reason is to investigate not the consequences of a particular decision, but the underlying value system that can be inferred from the decision.

The punch line of this paper is simple. Although Judaism has used a whole host of restrictions on competition and has had its share of legislation to promote private interests, there has been one area that has generally been a consistent exception to impediments to competition -- the teaching of Torah. This exception is all the more remarkable because those who were in a position to influence the legislation often stood to benefit from such restrictions. From this stress on teaching, the foundation was laid for the strategy that Judaism followed to insure its survival and perpetuation. We also show that the teaching was designed to influence both ritual and ethical behavior by influencing beliefs. The stress on both ritual and belief is important in light of the recent innovative and insightful work on religion (see, e.g., lannaconne 1992, 1994, 1998). In that work, the emphasis has been on explaining how groups can succeed in avoiding free rider problems by adopting behaviors that are costly. By sorting out free riders, the group can succeed in attracting and keeping active members who provide each other with 
collective goods (e.g., attendance at services, active participation, friendly environment, social interaction). There has been less emphasis in that work on understanding how the cult or religion creates values or affects beliefs. Indeed, in that literature, it is difficult to distinguish a bowling club from a religion. It is perhaps more accurate to describe that recent work as deepening our understanding of community formation in small groups. It provides insights into how a religion should internally organize for success. In this paper, we wish to bring to the forefront the desire of a religion -- Judaism in particular -- to alter beliefs and thereby alter actions, and at the same time to perpetuate itself.

Economists are trained to resist the notion that preferences are manipulable and focus instead on using prices as incentives devices. That is why, in part, religion has been regarded as an area outside of economics. But religion is a powerful incentive device that is used in regulating social and economic interactions. Unless economists wish to avoid what is one of the most powerful incentive mechanisms shaping history, they must face squarely the issue of the creation of values. ${ }^{1}$ Moreover, the emerging fields in business schools and elsewhere of entrepreneurship and leadership are closely related to the study of how religions can create values.

We begin in Section II with a simple model of religion focusing on altering beliefs and actions. We then take some initial steps in Sections II and III in trying to understand how a religion can create and perpetuate its values. In Section IV we turn to a description and analysis of the role of priests and prophets during the time of the First Temple and show that, although the priests were given exclusivity in carrying out sacrifices, and although, given their

1 There are at least two approaches to the topic "creation of values." The typical one is to assume that preferences are determined exogenously and to treat religion and culture as exogenous determinants of those preferences. An alternative approach is to treat the rules of the religion and culture as incentives designed to influence behavior and hence, at any instant, can be described as a system designed to cause an individual to behave "as if" the individual possessed certain values. If an individual behaves "as if" he has certain values, he may make economic (or psychological) investments so that his subsequent behavior will be well predicted by the "as if" values, even when the initial incentives change. We take the second approach. 
position, they had the ability and possibly even the moral right to corner the teaching market, they left open the teaching of Torah to all. We explain how this dichotomy established a precedent that was to influence subsequent generations and was a key force in explaining how Judaism survived. Section $\mathrm{V}$ discusses in some detail the attitudes toward competition in Jewish law since the Mishnah and shows the remarkable consistency in the preservation of competition among Torah teachers. Given the huge differences in economic circumstances among Jews over time and space, this consistency reveals the high value that Judaism placed on teaching the Torah with the ultimate result that Judaism has survived.

\section{A Simple Model of Religion}

Religion can have a powerful effect on behavior. Many religions attempt to shape the beliefs of their adherents with the result that their adherents alter their behavior. By making interpersonal behavior subject to divine scrutiny, a religion can induce desirable interpersonal behavior and in this way religion provides a low cost enforcement mechanism for inducing such behavior. For example, by making the rule to have honest weights and measures a divine commandment, the transaction costs of engaging in trade fall. The customer does not have to expend resources to verify the quantity of his purchase, and the state can spend less on enforcing honest behavior. Religion can therefore be a valuable mechanism for a state to use to help enforce its laws.

Let $\mathrm{R}$ be the rules (or more accurately their interpretation) of the religion, $a_{i}$ be the actions of individual $i, c_{i}$ be the consumption of individual $i$, and $u_{i}\left(c_{i}\right)$ be the utility of individual $i$. Let $P\left(R, a_{i}\right)$ be the divine penalty associated with actions $a_{i}$ (which might include consumption) given rules $R$, and let $\lambda_{i}$ be the individual's probability that a divine authority exists. The typical utility function for individual i depends only on that individual's consumption. We allow the penalty function to depend on more than consumption. In particular, it depends on the "distance" between the person's actions, and the actions specified by the "rules" laid down by the religion. 
So, for example, how one acquires income (honestly or not) could influence the penalty if the religion specifies that honesty is required. ${ }^{2}$ The penalty function could also depend upon the characteristics or actions of others, so that individual i could incur a penalty if others are hungry while individual i consumes lots of food. Thus, if, as in Judaism, the giving of charity (tzdaka) is required, the failure to do so implies a penalty, and thereby negatively affects the individual's utility. This means that, as a special case, there can be a penalty if the actions chosen by individual i deviate from the actions that would be chosen if individual i had a particular utility function -- such as one that specifies altruism wherein the utility of others matters to individual $\mathrm{i}$. So, for example, if the religion wants to encourage individuals to care about others, there would be a divine penalty anytime the chosen actions differ from those that the interdependent utility function would specify. ${ }^{3}$ Of course, the religion may also not want its followers to "overdo" it, and may place limits on the amount of "good" an individual may do in order to save one from himself. Thus, for example, in Judaism there is a maximum amount (20\%) of one's wealth that one is permitted to donate to charity.

A religion must supply answers to two basic sets of questions. First, how should the rules be chosen? In modern parlance, what is the religion's mission statement and contents? Second, once the rules are chosen, how does the religion cause people to believe that $\lambda_{\mathrm{i}}$ is sufficiently near one so that they will adhere to the rules? The two tasks are obviously related in that the rules are likely to affect $\lambda_{\mathrm{i}}$. For example, a new religion advocating child sacrifice would today have a difficult time gaining acceptance in most parts of the United States. Similarly, the actions of others could influence an individual's assessment of $\lambda_{i}$. Hence, $\lambda_{i}$ can depend on both $R$ and $Z_{i}$, where $Z_{i}$ stands for conditions outside of individual i's control, including, but not limited to, the actions of others as well as the individual's past actions. 
Individual i's expected utility is given by $U\left[c_{i}, a_{i} ; Z_{i}\right]=u\left(c_{i} ; Z_{i}\right)-\lambda_{i}\left(R, a_{i,-;} ; Z_{i}\right) P\left(R, a_{i}\right.$, $Z_{i}$ ) where $a_{i,-}$ is the individuals past actions, and where we have now explicitly incorporated the dependence of each relevant function on $Z_{i}$. The individual's budget constraint is given by $\Sigma p_{i} c_{i} \leq$ $I\left(a_{i}, Z_{i}\right)$, where $I$ is the individual's income which depends on $a_{i}$ and $Z_{i}$. Note, in particular, that one's actions affect one's income, but also affects one's utility. Treating $a_{i}$ as a continuous variable, in equilibrium $-\lambda_{i} \frac{\partial P}{\partial a_{i}}=\mu \frac{\partial I}{\partial a_{i}}$, where $\mu$ is the Lagrangian multiplier. This equality says that the marginal utility cost of one's actions is weighed against their monetary benefit. Note in particular that there is a feedback from actions into consumption. One may choose actions that would yield less than the maximal income, so consumption is altered by one's belief structure. $Z_{i}$ appears in the income function since others' behavior can affect the opportunities that are available to the consumer. $\mathrm{R}$ does not appear directly in the income function; rather the rules affect income through one's actions. In the absence of a belief in divine authority $\left(\lambda_{i}=0\right)$, individual i faces the usual consumer maximization problem. As $\lambda_{i}$ rises, the individual alters his behavior to conform to the religion's rules. The same effect occurs as the penalty rises. Therefore, belief and the penalty for actions that deviate from the rules are substitutes for each other in terms of affecting actions.

Assuming a Nash equilibrium, each individual chooses $a_{i}$ and $c_{i}$ to maximize his own utility, taking the actions and consumption of others as given. One immediate consequence is that it is quite possible in equilibrium for both $U\left(c_{i}, a_{i} ; Z_{i}\right)$ and $u\left(c_{i} ; Z_{i}\right)$ to be strictly greater when individuals believe in divine authority than when they do not. ${ }^{4}$ The reason is that the actions of others are altered by religion and this can benefit individual i, as occurs, for example, when religion causes individuals to act so that transaction costs fall. To take a simple example, if

$4 \quad$ Of course the effect on $u\left(c_{i} ; Z_{i}\right)$ could well go in the opposite direction, as the loss in personal freedom of choice (e.g., in Judaism, forbidden foods, limitations on activities permissible on the Sabbath, etc.) would tend to lower direct utility from consumption. 
religion forbids fraud at time of sale, then to the extent religion decreases fraud, it reduces the resources that firms would otherwise have to spend to detect fraud, causing trade to be less costly to engage in. Not only can believers $\left(\lambda_{i}=1\right)$ be better off than they would otherwise be, but so can non-believers. ${ }^{5}$ The non-believers can obtain benefits from the actions of believers. Indeed, religion can cause the actions of the non-believers to behave differently than they would otherwise because of the actions of the believers. If the actions taken by the non-believers cause them to prosper at the expense of believers, we would suspect that effect would reduce the number of believers. In such a case, we would expect the religious authorities, if they have the power to do so, to impose taxes or restrictions on the non-believers in order to reduce the incentive to become a non-believer. ${ }^{6}$

Religions will therefore have effects on the actions of both non-believers and believers. Although it is possible for a religion to make the actions of both believers and non-believers more in accord with its rules, the converse can also be true. ${ }^{7}$ For example, if the religion demands that sellers always accept the first offer of a buyer and that buyers must offer a price no lower than market price, a non-believing buyer would be able to offer a price of 0 and obtain the product from a believing seller. That is why the way in which the religion's rules affect interactions with non-believers may be critical in explaining its survival and why in many religions, including Judaism, behavior towards insiders is sometimes different than behavior toward outsiders. This reasoning suggests that successful religions will choose rules where actions of believers and non-believers are strategic complements (an increase in $a_{i}$ leads to an increase in $\mathrm{a}_{\mathrm{j}}$ ) and where the gains to believers exceed those to non-believers.

$5 \quad$ Non-believers could be worse off if the religious impose negative externalities on the non-religious. Thus, for example, the closing of streets on the Sabbath, restrictions on entertainment on the Sabbath, and restrictions on the availability of non-kosher foods negatively affect the non-religious.

6 See the appendix for simple examples of the principles laid down in this section of the paper in a game theory context, including an evolutionary analysis.

7 Using the language of Bulow, Geanakopolos and Klemperer (1985), the issue is whether the actions of the two groups are strategic substitutes or complements. 
After choosing a set of rules adherence to which will generate benefits, how does a religion create a group of believers? The behavior of others will matter in the formation of beliefs. There are at least two mechanisms at work. First, many psychological experiments show that people adapt their beliefs about probabilities in order to justify their actions and minimize the dissonance between their beliefs and actions (cognitive dissonance). Therefore, if one is constantly required to take observable actions, such as those associated with ritual, which make sense only if God exists, then one will revise upward one's probability of belief in God. Communal prayer, as is required in Judaism, is therefore one way of reinforcing or creating beliefs. Participating in ritual acts may be required if one is to avoid being ostracized from society. Individuals may dislike admitting they are engaged in ritual actions just for the sake of keeping their friends from jettisoning them, and so "adjust" $\lambda_{i}$ upward in order to justify their actions. That is why requirements not to deal with non-believers on the same terms as believers are potent tools to foster belief, especially when the relative number of believers is large. The notion that actions can affect belief (or preferences) is captured by the principle in Judaism that actions done without the proper intent will lead to them being done with the proper intent (mitoch shelo lishma ba lishma). So, for example, a selfish individual, forced continually to donate to the poor, will eventually donate willingly. This is the reason that we believe that $\lambda_{\mathrm{i}}$ is a function of past actions $\left(\mathrm{a}_{\mathrm{i},-}\right)$. $^{8}$

Second, suppose that individual i cares about his parents' (or friends') utility which depends on how he behaves. ${ }^{9}$ If his parents are believers, then the interdependence in utility will cause individual $i$ to act as if he is a believer. ${ }^{10}$ At this point, whether it is God or parents

8 Notice that belief in God is simply an intermediary step in creating "desirable" preferences. If an atheist develops these preferences, the religion has accomplished its goal. Cognitive dissonance could therefore work either through altering belief in God or by directly altering preferences.

9 See Becker (1974) for an analysis of interdependent utility functions within the family.

10 If parents care about their children's utility and independence of beliefs, then there could be a reverse effect. However, since parents tend to raise children to have similar beliefs to themselves, we would expect this reverse effect to be weaker than the one discussed in the text. 
that one is trying to keep happy is irrelevant for understanding behavior. ${ }^{11}$ Indeed, the extraordinary benefit one receives in Judaism for honoring parents highlights the importance of others in fostering belief. (The only commandment in the Ten Commandments for which there is a reward given in the commandment is the one about honoring parents -- the reward is so that "you" shall long endure. The "you" can be interpreted as the Jewish nation. [R. Saadya Gaon Exodus 20: 11]) By stressing honor due parents, Judaism reinforces the taking of actions that the parents approve of, and, by the preceding argument, will lead to a change in $\lambda_{i}--$ or equivalently to the transmission of beliefs and values from one generation to the next. ${ }^{12}$ This is another way in which $\lambda_{i}$ is a function of outside influences $\left(Z_{i}\right)$.

\section{Transmission of Values}

Once a religion is created, it will survive only if it can both transmit its central principles to succeeding generations while at the same time being adaptive enough to adjust to changed circumstances. Inflexible rules could create distortions that would impose, especially in changing circumstances, such huge costs that the net benefits of belonging to this group diminish. The recent studies of addiction (Becker and Murphy [1988]) and religion (lannacone [1992]), teach us that institutions or social capital have to be created and enhanced so that the costs of continuing in the group remain small. Exactly what constitutes successful survival strategies for a religion will depend on a whole host of factors, such as wealth, political power, and geographic dispersion of the population. A comprehensive theory of survival is a rich research question that we examine only in its relation to Judaism.

11 What happens when parents die, does their effect vanish? Not necessarily for at least three reasons. First $\lambda_{i}$ may have become large by the first mechanism (cognitive dissonance) and then remain high because a high $\lambda_{\mathrm{i}}$ is needed to justify past acts if one is reluctant to admit that their prior behavior was not a reflection of their own preferences. Second, the utility of individual i can depend on what his parents would have thought of his actions. Third, during his parents' lifetime, the individual may have made irreversible investments that create gains from continuing to be (or act as) a believer.

12 As parents of children whose age's range from 6 to 23, we are also well aware of the limitations parents sometimes have over their children's actions and beliefs. 
We discuss three factors that we believe are important in understanding Judaism's survival: its ability to reconcile its religion with hardship; its lack of political power which led to the accumulation of human, not physical capital; and its reliance on debate and decentralized teaching.

First, a religion that teaches that times will always be prosperous is unlikely to survive in the face of contradictory evidence. But when a group loses power, and is, for example, subjugated and impoverished, why would they not join another group? Why shouldn't they believe that they bet on the wrong God, and should switch? Although that undoubtedly occurred, sometimes in large numbers, Judaism introduced a crucial innovation relative to surrounding ancient pagan religions. That innovation was the lesson that even when times are bad, (and at least early on Judaism taught that times are bad because people have done wrong -- a position that has adherents to this day) God will never abandon the Jews and eventually prosperity will return provided the Jews return and follow the Torah (e.g., Leviticus 26: 3-13; Deuteronomy 28: 1-14). Such an optimistic belief guarantees not only that the necessary economic investments for prosperity will be made, but guarantees that the necessary investments in human capital, specifically the study of the Torah, will be made. ${ }^{13}$

Second, for most of their history, Jews have not had centralized political power. More typically they lived in foreign countries where, until the last two hundred years, their rights to own property and amass wealth was at the often unpredictable discretion of foreign powers. This suggests that physical institutions were unlikely to provide any necessary infrastructure. Hence, after the destruction of the Second Temple (70 CE), investments shifted almost

13 The Torah speaks of the collectivity of Jews following the rules. Because it is unclear what percentage must do so to avoid collective punishment, there could be a free rider problem even for a believer if the divine punishment to him were based solely on collective action and not on any of his individual actions. 
exclusively to investments in human capital. ${ }^{14}$ The development of Rabbinic Judaism (the Judaism of today) including the codification of the Mishnah, the debates that formed the basis for the Talmud, together with the continuing Torah commentaries and development of Jewish law represent this enormous investment in a body of knowledge that forms a historical inheritance for future generations. This body of knowledge continues to accumulate and provides a rich and portable form of social capital. If this knowledge is considered relevant, it represents an asset whose value is increasing over time. ${ }^{15}$ In terms of lannoconne's model, it explains how the odds of surviving can grow over time. But we must turn to the third feature of Judaism, its reliance on debate and decentralized teaching, to understand why this body of knowledge should remain relevant and valuable.

The dispersion of Jews across the world meant that the circumstances faced by Jews varied enormously. ${ }^{16}$ As is well known from the economics of franchising, the optimal response to widely varying conditions is to significantly decentralize decision-making. The trick, of course, is to do so without undermining the central body of rules and beliefs so as to cause the religion to splinter. ${ }^{17}$ One mechanism Judaism used to allow decentralization without splintering is to elevate the role of scholars who make decentralized decisions, but, at the same time, to give

14 Indeed, these investments in human capital began during the Babylonian Exile after the destruction of the First Temple (586 BCE). Many scholars believe that, during this time, the Torah was codified and brought back to Israel by Ezra and Nehemiah when they led the return from Babylon to Israel. A large Jewish community was likely left in Babylon where centralized animal sacrifice was not being practiced.

15 No doubt one response can be utter rejection of the relevance of the inherited wisdom. This did sometimes occur as, for example, in Western Europe during the 1800's and in Russia during the late 1800 's and early 1900's.

16 The Dalai Lama has studied Judaism to learn lessons for how his religion can survive now that he and many of his followers are separated because the hostile policies of the Chinese have forced him into exile in India. See Kamenetz (1984).

17 The content of the rules together with economic conditions will influence the incentive to take actions that deviate from the rules. As economic conditions change, the rules of a successful religion will have to adapt, otherwise the cost of remaining a believer may be too high. This reasoning would explain why in a cross section of the population one should expect a negative correlation between wealth and the level of adherence to the religious rules (those most able to prosper economically will find it in their interest to be least constrained by rules), but that over time in the face of economic growth, the rules of the successful religion should change (e.g., to conserve time as labor increases in value) but the overall religiosity of the society should not. 
greater precedential weight to older scholars and commentators. In this manner, poskim (scholars who set the law) can be divided into four groups according to chronological order Tana'im, Amora'im, Rishonim and Acharonim. The Tana'im are those scholars who lived during the time the Mishna was composed (until about 200 CE) - they are the Rabbis cited in the Mishnayot. The Amora'im were the Rabbis during the period of the Gemara (until about 500 $\mathrm{CE}$ ), the Rishonim were the early commentators (until about $1550 \mathrm{CE}$ ), and the Acharonim are Rabbis from then until today. It is clear from the Talmud that an Amora never disagreed on a point of law with a Tana unless there was another Tana to back his opinion up. Similarly, in later responsa, commentaries and codifications, Rishonim never set law in disagreement with Amora'im, and Aharonim never disagreed on a point of law with Rishonim. Such a hierarchy also appears within categories, strictly based on chronology. ${ }^{18}$ This technique demands that even radical reformers must have a thorough knowledge of the historical tradition.

The model Judaism followed was to discuss and debate from a common text. ${ }^{19}$ This model creates at once a connection to tradition and a built-in adaptive mechanism. The power of this approach is that, even though separate communities can pursue different paths and interpretations, they can remain identified as the same religion. Consequently, despite the existence of some quite different laws and customs across communities, the study of Torah has remained central in all Jewish communities. ${ }^{20}$ ("The study of Torah is as important as all the mitzvot combined." ${ }^{21}$ ) Perhaps the most striking current example is that of Ethiopian Jews whose isolation from other Jews for at least 1000 years did not prevent them from being recognized as Jews and being reabsorbed (but not without significant difficulties) into Israel.

18 The Midrash says that there is a continual lessening of understanding of the Torah as we move further away chronologically from receipt of the Torah at Sinai.

19 Much of Jewish study, especially Talmudic study, is not about rules but about interpretation and debate. The Talmud poses far more questions than it answers and, in sometimes excruciating detail, reports various sides of an argument.

20 For example, among Ashkenazi Jews polygamy was banned about 1000 years ago, but this ban did not apply to Sephardic Jews until recently.

21 Shabbat $127 \mathrm{a}$ 
The knowledge of Torah and the adherence to halacha (Jewish law) immediately linked a population isolated in a primitive economy to their modern co-religionists.

The only way to transmit the knowledge of a religion's rules from one generation to another is to teach it to the younger generation. And, presumably, the best teachers will be highly prized for playing a key role in perpetuating knowledge (or, alternatively, in interpreting the rules in a way that is both engaging and sensible in light of the circumstances). In Judaism, the Torah teaches that the parent has the responsibility to teach his children Torah. ${ }^{22}$ To the extent that parents do try to teach Torah, this creates an incentive for parents to become better informed about the Torah than they would otherwise be. As every teacher knows, the best way to learn material is to be required to teach it. No teacher wants to be embarrassed by lack of knowledge before one's students, especially when the students are one's own children. Interestingly, the placing of the responsibility of teaching Torah on the parents makes both the parents and the children more knowledgeable about Torah. However, specialization produces gains so there is a trade off between having a parent (who may be ignorant) try to teach instead of a trained teacher. The obligation of a parent can be discharged by hiring a teacher, but even here the parents' duty would be to remain involved with the teaching. The value of specialized teachers was recognized early in Judaism and, as we report in Section IV, public education was instituted around the first century BCE.

Competition among Torah teachers fosters the goal of creating high quality decentralized education. It also is a surefire way to simultaneously transmit a common heritage and allow

22 See, e.g., Deutoronomy 6:5-9. This passage (“ ... Take to heart these commandments ... Teach them to your children. Recite them when you are at home and when you are away, when you lie down and when you arise ... inscribe them on the doorposts of your house ...") is said three times each day by observant Jews and both Orthodox and non-Orthodox Jews commonly affix this prayer to their doorpost (mezuzah). 
adaptation to changed circumstances. ${ }^{23}$ We now turn to a more detailed discussion of the rules aimed at competition among teachers.

\section{Early Period - Until Destruction of First Temple}

The teaching of Torah was not the central religious activity of the early Hebrews.

Instead, animal sacrifice was. The priests were assigned the exclusive right to perform these sacrifices, which were used in part to support the priests. Perhaps because sacrifice was so important to the early Israelite religion, severe restrictions and fights on who could perform religious rites (and how) proliferate (e.g., the story of Korach, the story of Aaron's two sons, the conflict between the Aaronite priests centered in Jerusalem and the Levitical priests elsewhere) ${ }^{24}$ Although the priests were the exclusive agents to perform animal sacrifice, it would appear that the priests were not the exclusive agents to disseminate or interpret the Torah. Indeed, quite the opposite appears true. Each father is charged with the responsibility to teach his sons the Torah [Deuteronomy 6:5-9] and the Torah emphasizes that it should not be regarded as esoteric laws known to only a select few. As the Torah explicitly states [Deuteronomy 30:11-14] "For this Instruction (i.e., the Torah) which I command you today is not hidden from you nor distant from you. It is not up in the heavens to say 'who will go up to the heavens and take it down for us and tell it to us so we can do it'. Nor is it across the sea to say 'who will cross the sea for us to take it and tell us so we can do it'. For it is very close to you, in your mouths and hearts to do it." This passage from Deuteronomy could reflect the decision by Josiah to centralize the economically important sacrifices in the Temple in Jerusalem and

23 Although the discussion in this section has focussed on Judaism, the underlying ideas are applicable to any religion. So, for example, it is a general principle that the benefits of decentralization of authority are its greater ability to adapt over time and over space to disparate conditions. One would therefore expect religions (e.g., Catholicism) with a very central hierarchy to change slowly, to have difficulty in countries where its central hierarchy is not politically supported, and to work best when applied to relatively homogeneous groups. In contrast, religions (e.g., Protestantism) with less hierarchical structure should be able to change faster and be better suited for turbulent times and heterogeneous populations. 
decentralize the (then) less important function of teaching. Moreover, it is clear that the prophets play an important role in disseminating God's commandments and the prophets are not drawn exclusively from the class of priests or from any other closed social group. In short, in the time of the First Temple, performing sacrifices, not teaching, was the service with exclusivity.

And yet, the Kohanim had the right to demand such exclusivity in teaching. ${ }^{25}$ The Levites were not given a part of the land of Israel - instead their portion was in the service of the Lord, and each tribe supported the Kohanim and Levites in their midst. Part of this job of servicing the Lord was in the dissemination of the Torah, as written in Malachi (Ch. 2 v. 7 ) "For the lips of the Kohen will keep thought and the Torah will be requested from his mouth, for he is the Angel of the Lord", with the meaning of the first section being that this is one of the jobs given to the Kohanim.

Why is it that the priests did not seek exclusivity in teaching, despite already having such exclusivity in the giving of sacrifices? Possibly, someone may have recognized the benefits that competition brings and realized that restricting competition in teaching would be undesirable for belief and knowledge transmission. Or, possibly, the initial economic value of cartelizing teaching may have been small, especially in comparison with the economic value of controlling sacrifices, upon which early Judaism was based. By the time centralized animal sacrifice temporarily ceased, after the destruction of the First Temple (586 BCE) and during the subsequent Babylonian exile, the precedent that teaching was not restricted to the Kohanim may have been firmly established and become too difficult to change, especially in light of the loss of power of Israel to Nebuchadnezar. Whether motivated by altruism, miscalculation, historical accident, divine intervention, or dumb luck, the decentralization of Torah teaching

25 The Levites (one of the twelve tribes) comprise the priestly class. The Kohanim are members of the tribe of Levi and are descendants of Aaron. 
beginning at the period of the First Temple set an important precedent that, as we will see, was followed by later generations.

Our analysis about the role of priests in teaching and sacrifice differs from the insightful analysis of Raskovich (1996) who uses the theory of vertical restrictions involving price and territory to understand the role of priests. He argues that the priests were assigned exclusive territories and were required to charge fixed prices (the Torah specifies the in kind payment that the priest can retain from the sacrifice) thereby creating incentives for the priests to compete with each other through the provision of religious services -- such as teaching Torah. ${ }^{26}$ However, Raskovitch's hypothesis that priests did not compete on price is undermined by his own analysis, which recognizes that Levites raised animals that were likely sold for sacrifice. Price competition could occur through lowering the prices for the priest's animals. With price competition occurring, the incentive to provide services, such as teaching, vanishes. Moreover, we note that there is some uncertainty among historians regarding the importance of the in-kind sacrifice payment to priests who were also supported by the wealth of the Temple. If priests were supported primarily by the wealth of the Temple and not by the in-kind payments, then there would not be the incentives that Raskovich discusses to provide services such as the teaching of Torah. We therefore disagree with the preeminent role that Raskovitch suggests that the priests had in teaching. ${ }^{27}$

Aside from their role in teaching, the prophets, and not just the exclusive class of priests, play an important role in belief transmission. Recall our earlier discussion about how beliefs could be created in an environment in which everyone is encouraged to engage in rituals in order to avoid ostracism by the existing believing community. The prophets urged the Israelites

26 In the usual theory of vertical restrictions (see, e.g., Carlton and Perloff [1999] Chapter 13) the territorial and price restrictions channel a firm's competitive incentives into the provision of services to attract customers. It also follows that with restrictions on competition, priests would benefit from prophets whose exhortations should have increased demand for the priests' services. However, we are unaware of any suggestions that priests paid prophets. (See Kaufman [1956] page 59.) Despite these differences with Raskovich, we recommend his paper and thought provoking arguments. 
to follow all the Torah's teachings, both those involving ritual and those involving ethics. (The Torah makes no distinction between the two and in some instances one can debate which category a particular law fits into.) The prophets also railed against performing only the rituals (e.g., sacrifices) unless one also acted in accordance with a belief in God (e.g., Isaiah 58). The prophets wanted to raise $\lambda_{\mathrm{i}}$ which would then affect both interpersonal actions and sacrifice. On the other hand, given their exclusivity in the performing of sacrifice, the priests should have cared only about increasing the demand for sacrifice regardless of whether other actions were affected. Accordingly, the prophets, not the exclusive tribe of priests, were critical in transmitting Torah and beliefs that translated into actions. ${ }^{28}$

\section{Rabbinic Judaism - Attitudes toward competition ${ }^{29}$}

The Talmud followed by the subsequent codifications of Jewish law together with the responsa literature provide a rich source of information regarding restrictions on competition over the last 2000 years. Because the conditions under which Jews have lived over the centuries have varied so much, and because restrictions in one set of circumstances may not make sense under another, one should be wary about leaping to any general principles that

28 In the language of agency theory, the priests received a reward (sacrifice some of which they kept) when the population understood rules specifying sacrifice, but not when the population understood the rules specifying interpersonal conduct (with the exception of sin offerings). Because of their skewed incentives, priests should be expected to have promoted sacrifice over ethical interpersonal conduct.

We draw on the excellent discussions in Levine (1980) and Tamari (1987). We are especially grateful to Aaron Levine and Rabbi Gershon Seif for helpful conversations. We have skipped much of the period of the Second Temple. Briefly, the exile of the Jews to Babylon forced them to develop the religion without the central reliance on animal sacrifice. The leadership of Ezra and Nehemiah in instituting regular readings of the Torah on market days (Mondays and Thursdays -- a custom followed to this day) when they returned from Babylon to Israel (around 400 BCE) established a systematic attempt to teach Torah regularly. The reforms, promulgated by Yehoshua ben Gamla (Bava Batra 21a) somewhere around the first century BCE, instituted education supported by a community tax for all over the age of 6 or 7 . Until Yehoshua ben Gamla (a High Priest during the time of the Second Temple), Torah was taught only by fathers to their sons, and teaching by scholars was done only from the age of 16-17. Those without fathers, and those whose fathers were unable to teach, did not learn Torah. It is stated (Bava Batra 21a) that but for the decree by Yehoshua ben Gamla, Torah would have been forgotten from Israel. The drawback of this reform is that the parents' incentive to learn Torah was lessened. The advantage is the gains from specialization in teaching. 
would apply under most or all economic conditions from an observation on the laws prevailing in one particular place or time. However, we find a remarkable consistency in the lack of restrictions on teaching across a wide variety of circumstances. This allows us to infer a general conclusion regarding the value that Judaism places on education. ${ }^{30}$

Although Judaism is generally described as having a favorable view toward competition (e.g., Tamari [1987, p. 86]), Judaism has restricted competition on many occasions. We will summarize two general restrictions on competition, hasagat g'vul (yored le'omanut chavero) and herem hayishuv. In both cases, there is a strong general exception to impeding competition for Torah teachers, a position which would not be consistent with the self-interest of Torah teachers who would desire to restrict entry. ${ }^{31}$ As we shall see, this lack of self interest contrasts with other instances of restrictions on competition that were designed to protect select groups. This lack of self-interested legislation protecting teachers is noteworthy because the Rabbis who had the ability to promulgate such rules and who would have benefitted from such rules chose not to

30 In speaking of "the value that Judaism places on education," we are not propagating the view that there is one central decision maker in Judaism whose preferences we are uncovering. Rather, we have taken the view that the result of any decision is the consequence of various conflicting political and economic interests among different groups. The outcomes of those conflicts are observable and one can then talk of those outcomes reflecting "underlying values" but such talk is imprecise. The analyst observes the outcomes of an equilibrium, not the underlying demand (or supply) curve for, say, education.

31 If teachers are not paid, then all this discussion about free entry is quite beside the point. In fact, although there are clear sentiments in the Talmud expressing disapproval of payment (e.g., Nedarim 36b-37a, Pirke Avot Ch 4 Mishna 5 and later codifications [e.g., Rambam (b. 1135 CE), Mishna Torah, Laws of Talmud Torah 1: 7]), the practicalities clearly prevailed requiring teachers to be paid. As just discussed in Footnote 29, during the Hasmonean period, communities were required to tax themselves to insure that teachers would be provided. The Talmud explains that teachers could also be considered "babysitters" and so could be paid, or, alternatively they could be paid to teach the punctuation of the Torah (which is not considered part of the Torah since Torah scrolls are written without punctuation) (Nedarim 37a). Rambam explains that if a father could not fulfill his responsibility to teach his son, he is required to hire a teacher. R. Moshe Feinstein (b. 1895) cites R. Moses Isserles for the opinion that being paid for teaching is necessary for practical purposes - "in order to push along Torah, push it [in reference to a hostile attitude regarding payment in the Shulchan Aruch] aside". The bottom line is that compensation for teaching appears common. 
do so. ${ }^{32}$ This does not mean that scholars never had self-interested rules promulgated in their favor. Quite the contrary, scholars receive lots of special rulings and, in general, were held in high esteem. For example, scholars were exempt from paying taxes in walled cities, scholars were exempt from the entry restriction on setting up shops selling cosmetics (Bava Batra 22a), and scholars are given priority in bidding for certain property (Shulchan Aruch). It is only in the competition to teach that scholars generally get no respite. ${ }^{33}$

The general restrictions on entry often come under the category hasagat g' vul -- the removal of a neighbor's landmark. The Rabbis extended the concept of hasagat g'vul to cover encroachment on another's business. We begin our analysis of entry restrictions with Bava Batra $21 \mathrm{~b}$, in which $\mathrm{R}$. Huna rules that the resident of an alley with a business in that alley can prevent a resident of another alley in the same town from opening a competing business. In contrast, R. Huna ben R. Joshua argues that entry cannot be prevented if the entrant is a resident of another town and pays taxes to this one. Moreover, if the entrant is a resident of the same alley, he cannot be prevented from competing. The opinion of R. Huna ben R. Joshua prevails. What remains unresolved is whether the entry into one alley by a resident of another alley in the same town is allowed. Despite this disagreement, there is a long discussion in Bava Batra 21a that one cannot block entry related to the teaching of children. R. Huna concedes (Bava Batra 21b) that even his protectionist views would not apply to those who teach Torah.

32 We have tried to come up with explanations based on self interest for this exception but don't find our possible explanations particularly convincing. Two possible explanations are as follows. First, the Rabbis who set the rules (Poskim) are usually not those who teach children. The Poskim tend to teach advanced students who themselves become Rabbis and teachers. Thus, the consequence to restricting the number of teachers would be to reduce the supply of students with a resulting decline in the future supply of both teachers and Poskim, driving up wages of both teachers and Poskim. On the other hand, if (as seems unlikely) the supply of Poskim is independent of the supply of teachers, then Poskim self-interest may be served by increasing the number of teachers and thereby the demand for Poskim services. Second, restrictions on entry create a benefit to local incumbents. If teachers highly value mobility (e.g., to be close to centers of learning) then they would prefer to not have entry restrictions.

33 It is useful to distinguish entry restrictions from content restrictions. We speak only of the former in this paper. The use of excommunication to ban heretical ideas was not uncommon. However, entry restrictions would have allowed even more content restriction. 
The discussion in the Talmud makes clear that each teacher is fearful that a rival will outperform him, and this fear spurs extra effort with the consequence that more knowledge is disseminated. The thrust of this discussion is the clear recognition of the benefits of competition and the paramount importance of teaching as a central value of Judaism. Indeed, this high regard for education explains why teachers were one of the five groups who can be dismissed without notice if they commit a grievous error. (The other groups are professional tree planters, butchers, bloodletters, and town scribes. Bava Batra 21a.) This high regard for Torah education also explains why Torah teachers are exempt from certain "zoning" rules. For example, the Mishna states that if a shop is set up in a residential area, the residents can shut the shop down if they find that the noise of people coming into the shop disturbs their sleep. This rule, however, does not apply if the noise comes from students attending Torah classes (Bava Batra 20b). In our view, the emphasis placed on free competition in teaching reflects the strategy that Judaism chose to follow to survive -- decentralized teaching.

In subsequent decisions on general restrictions on competition, the free entry view of $\mathrm{R}$. Huna ben Joshua was not always followed. R. Moses Isserles (born [henceforth b.]. 1525) indicates in an approving discussion of a protectionist ruling by R. Eliezer ben Joel ha-Levi (b. 1140) of Bonn that deprivation of an incumbent of his livelihood can justify entry restrictions. However, elsewhere, R. Isserles appears to reject a protectionist view. R. Moses Sofer (b. 1762) similarly adopts the view that financial ruin can justify entry restrictions. R. Moshe Feinstein (b. 1895) agrees and goes further to add that the reduction in the incumbent's earnings below the average of his peer group can justify entry restrictions. Under the protectionist's view, these general entry restrictions do not apply if the financial ruin is due to the incumbent's unwillingness to become more efficient. However, if the incumbent lacks the ability to become more efficient, then protection is accorded. In other words, under the protectionist rulings, a firm with a superior technology can be prevented from entering and competing if the result would be financial ruin of the incumbent. 
We find the protectionist rulings to be in accord with many entry restrictions in modern times -- often supported by special interest groups. However, we note that the primary concern expressed in these protectionist opinions has been with the financial ruin of the incumbent. One plausible interpretation is that financial ruin of a resident creates a hardship to that community. The resident may need to be supported or could otherwise cause problems to the community from idleness. ${ }^{34}$ We simply note that these concerns should be of less relevance in a modern economy in which there is both labor mobility and a social welfare net. In such cases, restrictions on competition are exactly what they seem -- special interest legislation. There would seem to be only a weak basis in even the protectionist view of Jewish law for such legislation.

These protectionist rulings would appear to leave open the possibility that a teacher could be prevented from entering into competition if financial ruin of the incumbent was likely. However, we note that the authoritative code of Jewish law, the Shulkan Aruch (mid 1500's) states, "If there is a teacher of children and another comes who is better, the better teacher must replace the incumbent." (Yorah Deah: 245:18). Moreover, according to R. Joseph Saul Nathanson of Lemburg (b. 1810), the freedom of movement that Torah teachers of children possessed must also apply to teachers of Talmud on the Talmudic grounds already discussed as well as on the legal fiction that there can be no financial deprivation because the income that such teachers earn should not be regarded as direct wages. (See Levine p. 17). R. Moses Sofer (b. 1762) (who we just discussed as supporting a protectionist view on entry in the case of financial deprivation) is opposed to entry restrictions on any religious ministrant to the extent the person would produce rivalry in Torah teaching. (Levine p. 18). To the extent that there remained any uncertainty about the application of protectionist rulings to education, some recent

34 Hence, it may be more efficient to allow an interference in competition than not. In the case of teaching, the externality that teaching creates (survivability) generally trumps any concern with financial distress. 
cases have resolved the issue. The highest rabbinical tribunal in Israel has stated that it would not prevent competition from a rival religious teacher and, in another case, it refused to restrict entry into the publication of the Talmud without regard to the possibility of financial deprivation (see Levine p.32). ${ }^{35}$ These views are in accord with the high value placed on teaching and dissemination of knowledge in Judaism.

The other major doctrine used to prevent entry is herem hayishuv. ${ }^{36}$ The doctrine was used to prevent outsiders from settling in a town, and thereby start competing with residents. Unlike the case of hasagat g'vul where the tax payment of outsiders allowed them to enter and compete, no such principle applied here. The doctrine was used commonly throughout medieval times, in parts of Western Europe (France, Germany, Italy, and England) and Eastern Europe. The doctrine was not applied in Muslim countries where Jews were often under less severe economic restrictions than in Christian Europe regarding the activities that the ruling authorities allowed Jews to do. Despite the view in major codes (e.g., Mishnah Torah, Shulkan Aruch) endorsing the free entry philosophy of R. Huna ben Yehoshua, these herems were widespread and would appear to be of much greater significance in restricting entry than the doctrine of hasagat g'vul. However, religious teachers were one of the notable exceptions (another was refugees) (Tamari, p. 115). ${ }^{37}$ That is, even when economic circumstances were so dire as to cause (with rabbinic approval) general entry restrictions to be promulgated in clear

35 A possible exception to this generally favorable view of competition among scholars is R. Moshe Feinstein's (b.1895) ruling preventing the establishment of a synagogue near another (Igrot Moshe Responsa Choshen Mishpat:1:38). However, Feinstein makes clear that this ruling does not apply to teachers and that it is only to the non-teaching functions of the synagogue that it applies. One interesting feature in this ruling is the notion that, if a competing synagogue enters for non-livelihood reasons (e.g., altruistic reasons) and, for example, the rabbi takes no pay, then that competition can be prevented by an incumbent who does derive a livelihood.

36 See e.g., Rabinowitz (1945) and Tamari (1987, p. 113).

37 Rabbis were one of the categories of exception. However, toward the end of the 700-year period during which the herem operated, Rabbis were able in some locations to prevent entry of other Rabbis apparently on the grounds that Rabbis performed some functions that were non-educational. We are unaware of a systematic use of a herem against teachers. However, we are aware of one case where a herem was used in Italy against a religious teacher in the late 1400's. Interestingly, Italy also has a case where it applied the herem to prevent entry of refugees, another of the usual categories of exception to the herem. (See Rabinowitz, Ch. 10.) 
violation of Talmudic principles (specifically free entry of out of town residents who agree to pay taxes), such entry restrictions on teachers were uncommon.

There undoubtedly were some cases under both the hasagat g'vul and herem hayishuv doctrines where interest groups may have succeeded in placing entry restrictions on teachers (though, other than the exception noted in footnote 37 , our search of the responsa literature failed to reveal any such cases). Our point is that there was generally a distinction between teachers and other occupations in the placing of entry restrictions and that generally teachers were free of such entry restrictions.

\section{Conclusion}

A religion consists of a belief in God combined with rules that God wants adherents to follow. Each religion must follow some strategy to survive. Judaism wound up following as its strategy the decentralized teaching of Torah. From its very beginnings, the teaching of Torah became a familial obligation and then later a communal one. Unlike sacrifice, teaching was not the realm of a select few. This failure of any interest group to relegate Torah teaching to itself carried over to Talmudic times and later. While restrictions on general competition arose, Torah teachers typically were free of any such restrictions. It is particularly remarkable that the scholars -- who were in large part in control of Jewish law -- generally chose not to close their profession or enact restrictions on entry but instead chose to keep competition thriving in their profession. As the Talmud recognizes, there are benefits to such competition: "Jealousy among scholars increases wisdom." 38

38 Bava Batra 21a. 


\section{$\underline{\text { References }}$}

Becker, G. (1974). "A Theory of Social Interactions," Journal of Political Economy 82: 10631093.

Becker, G. and K. Murphy (1988). "A Theory of Rational Addition," Journal of Political Economy, 96: $675-700$.

Bulow J., J. Geankopolos and P. Klemperer (1985). "Multimarket Oligopoly: Strategic Substitutes and Complements," Journal of Political Economy, 93, 488-511.

Carlton, D. and J. Perloff (1999). Modern Industrial Organization, Harper Collins.

lannaconne, L. (1992). "Sacrifice and Stigma: Reducing Free Riding in Cults Communes and Other Collectives," Journal of Political Economy, 100:271-291.

lannaconne, L. (1994) - "Why Strict Churches Are Strong," American Journal of Sociology, 99:1180-1211.

Iannaconne, L. (1998) - "Introduction to the Economics of Religion," Journal of Economic Literature, 36:1465-1495.

Kamenetz, Rodger (1994). The Jew in the Lotus, Harper Collins.

Kaufman, Y. (1956). "Israel in Canaan and The Age of Classical Prophecy," in Great Ages and Ideas of the Jewish People, ed. Schwartz, L.

Levine, A. (1980). Free Enterprise and Jewish Law, Ktav Publishing.

Miller, Geoffrey (1993). "Rituals and Regulations," Journal of Legal Studies, 477-501.

Rabinowitz, L. (1945) The Herem Hayishub, Edward Goldston, London.

Raskovich, A. (1996). "You Shall Have No Other Gods Besides Me: A Legal Economic Analysis of the Rise of Yahweh," Journal of Institutional and Theoretical Economies, "p. 449-471.

Tamari, M. (1987). With All Your Possessions, The Free Press. 


\section{Appendix}

\section{Strategic Behavior I-A Two-Person Game}

Assume there are two individuals - one with a high value of $\lambda$ and one with a low value of $\lambda$. Each can decide to act religiously $(R)$ or non-religiously (NR). The payoff table might look something like this:

\begin{tabular}{|c|c|c|c|c|}
\hline \multirow{10}{*}{ Low $\lambda$ player } & & & \multicolumn{2}{|c|}{ High $\lambda$ player } \\
\hline & & & $\mathrm{R}$ & NR \\
\hline & $\mathrm{R}$ & & 4,5 & 1,3 \\
\hline & & & & \\
\hline & ND & h) & 51 & 6,2 \\
\hline & & & , & \\
\hline & & c) & 7,1 & \\
\hline & & d) & 3,3 & \\
\hline & & e) & 5,3 & \\
\hline & & & 7,3 & \\
\hline
\end{tabular}

The high $\lambda$ player prefers that both act religiously. If, however, the low $\lambda$ player acts nonreligiously, the high $\lambda$ player may still be better off if he acts religiously (cases $d$, e and f) than if he does not. This would depend on the magnitude of the "penalty" discussed in the text. For the low $\lambda$ player, the worst case scenario is when he acts religiously and the high $\lambda$ player does not. However, when the high $\lambda$ player acts religiously, the low $\lambda$ player may be better off (cases a and d) or worse off (cases b, c, e and f) from also acting religiously. In fact, as in cases c and f, he may be better off when the high $\lambda$ player acts religiously than when he acts non-religiously (as per the externality discussed in the text).

The Nash equilibria are as follows:

In case a) there are two pure strategy equilibria - R-R and NR-NR. Similarity is important, and it is unclear whose beliefs will prevail. 
In cases b) and c) - NR-NR. In this case the negative externality on being different is great, and since NR dominates for the low $\lambda$ player, it is also chosen by the high $\lambda$ player.

In case $d)-R / R$. Again there is an externality, but in this case there is a dominant strategy for the high $\lambda$ player, so his desires prevail.

In cases e) and f) - NR/R. In this case only do we get heterogeneity in actions.

\section{$\underline{\text { Strategic Behavior II - Evolutionary Considerations }}$}

Assume for simplicity that there are two types of players, those for whom $\lambda=0$, and those for whom $\lambda=1$. Each player in the economy interacts with each other player in the economy an equal number of times. Players for whom $\lambda=1$ will always act in a religious manner $(R)$, since the penalty for not doing so outweighs other considerations. However, those for whom $\lambda=0$ can act as if $\lambda=1(R)$. Assume that in the initial equilibrium all those for whom $\lambda=0$ act non-religiously (NR), and that the share of $\lambda=1$ people in the population equals $\alpha$. The payoff table for the $\lambda=0$ individual would look something like this:

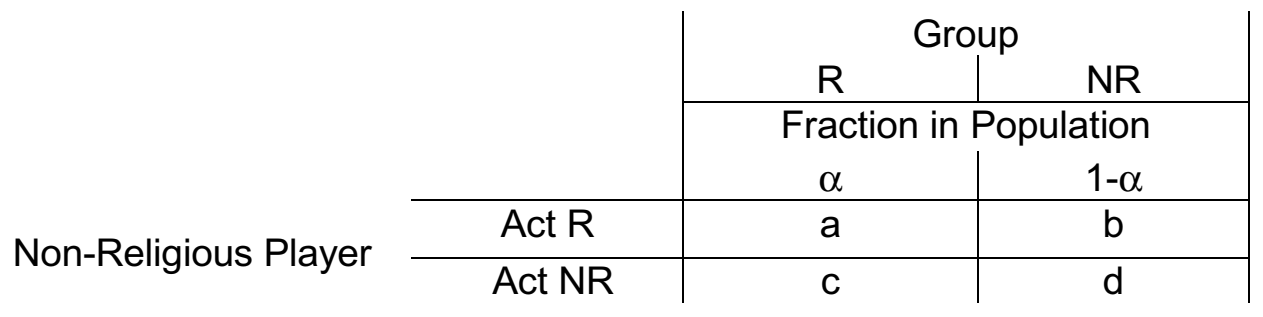

The player, has to decide whether to remain true to his beliefs and act NR, or to act $\mathrm{R}$. We assume that each person prefers to deal with his own kind. Hence, the reward one will receive if 
the person who is dealing with him believes that they are alike is greater than if that person believes they are different. This assumption amounts to assuming that $a>c$ and $d>b .^{39}$

When $\alpha$ is small, there are two equilibria -1 ) all $\lambda=1$ people act $R$ and all $\lambda=0$ people act NR, and 2) all people act R. Assume that the first equilibrium holds initially. If $\alpha$ grows sufficiently large, the $\lambda=0$ player will prefer to act $R$ rather than $N R$, even if all other NR people act NR. At this point all $\lambda=0$ people will act R. To be precise, this will occur when $\alpha>(d-b) /((d-$ b) $+(a-c))$. (Note that under the assumptions above regarding the relative sizes of these parameters, $0<\alpha<1$.)

Other assumptions are, of course, possible. If, for instance, the honesty argument given in the text prevails, it is possible that $b>d$ since one always do better dealing with an $\mathrm{R}$ person than with an NR person. In this case, acting R dominates.

We now expand this analysis to include a third person, for whom $0<\lambda<1$. We will denote this person SR (for semi-religious). We now assign a payoff table based on the following assumptions:

- The proportion of SR players in the population is $\beta$.

- The more similar the player is to the person with whom he is dealing the greater the payoff.

These assumptions lead to the following payoff table for all but the religious person (whom, we recall, always acts $\mathrm{R}$ ).

39 We could alter this assumption slightly to say that the player deciding how to act receives greater benefit from dealing with one of his own, so that $d>c$ and $a>b$. This will not change the conclusions at all. 


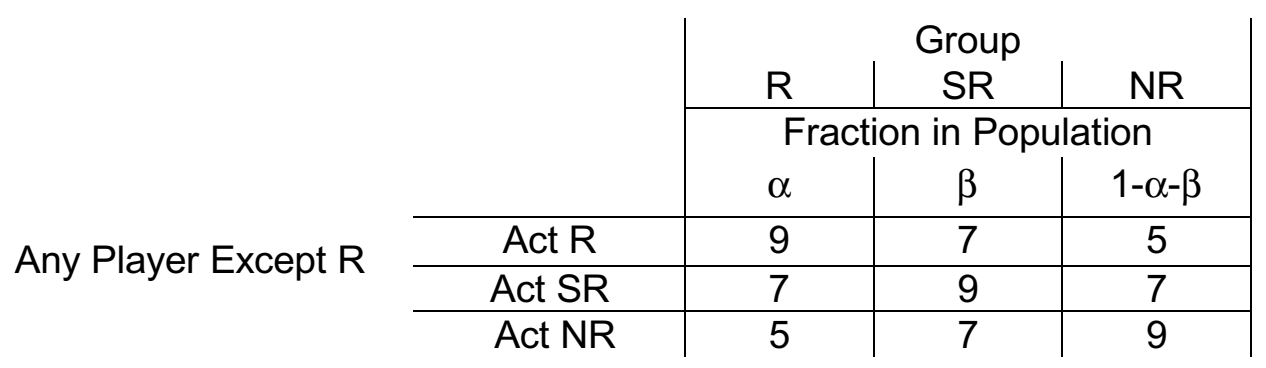

We now add the following assumption:

- There is a cost to acting differently than you are, and this cost grows as you change your behavior more.

This yields the following table for the SR player:

\begin{tabular}{|c|c|c|c|c|} 
& \multirow{2}{*}{} & \multicolumn{4}{|c|}{ Group } \\
\cline { 3 - 5 } & & \multicolumn{3}{|c|}{ Fraction in Population } \\
\cline { 2 - 5 } Semi-Religious Player & \multicolumn{2}{|c|}{ SR } & NR \\
\cline { 2 - 5 } & & $\alpha$ & $\beta$ & $1-\alpha-\beta$ \\
\cline { 2 - 5 } & Act R & 8 & 6 & 4 \\
\cline { 2 - 5 } & Act SR & 7 & 9 & 7 \\
\hline Act NR & 4 & 6 & 8
\end{tabular}

Solving the resulting inequalities, the SR player will act $R$ if $\alpha>3 / 4$, and will act NR if $1-\alpha-$

$\beta>3 / 4$. The table for an NR player is different given the penalty associated with deviant behavior, and looks like this:

\begin{tabular}{|c|c|c|c|c|} 
& & \multicolumn{4}{|c|}{ Group } \\
& & $\mathrm{R}$ & $\mathrm{SR}$ & $\mathrm{NR}$ \\
\cline { 3 - 5 } & & \multicolumn{3}{|c|}{ Fraction in Population } \\
& & $\alpha$ & $\beta$ & $1-\alpha-\beta$ \\
\cline { 2 - 5 } Non-Religious Player & Act R & 7 & 5 & 3 \\
\cline { 2 - 5 } & Act SR & 6 & 8 & 6 \\
\cline { 2 - 5 } & Act NR & 5 & 7 & 9
\end{tabular}

The NR person will also act R if $\alpha>3 / 4$, and will act SR if $\alpha+\beta>3 / 4$ and $\alpha<3 / 4$. 
The above examples may help in understanding a fairly recent trend in religious observance. There is a feeling that the level of observance in religious communities has been increasing. This could be understood in our model by noting the markedly higher birth rates among the religious than among the non-religious. Since these higher birth rates lead to higher values for $\alpha$ (and possibly $\beta$ ), greater portions of the population will decide to act semireligiously (as $\alpha+\beta$ increases) and then religiously (as $\alpha$ increases). Moreover, as stated in the text, mitoch shelo lishma ba lishma - cognitive dissonance can lead people who behave in a religious manner to increase their values of $\lambda$-- further reinforcing the trend toward greater religious observance. 